\title{
Los conflictos por la supremacía del poder virreinal en una tradición de Palma
}

Por Iván Rodríguez Chávez 
Doctor en Educación. Abogado. Poeta y ensayista. Rector de la Universidad Ricardo Palma. Ha sido presidente de la Asamblea Nacional de Rectores. Estudió en la Universidad Nacional Mayor de San Marcos. 


\section{Una consideración previa}

Si se aprecia al conjunto de todas las tradiciones escritas sobre el virreinato peruano por Ricardo Palma, se llega a la conclusión de que ellas conforman una pintura completa de la sociedad colonial, y de cuyo todo se pueden desprender informaciones sobre cualquier aspecto de la realidad que sea materia de estudio particular. Tal el caso del Derecho, conforme se tratará de mostrar en este pequeño artículo.

En esta oportunidad hemos escogido la titulada $U \boldsymbol{n}$ virrey hereje y un campanero bellaco, integrante de la segunda serie, aparecida en Lima en 1874.

\section{La Tradición}

\subsection{Forma}

Como especie narrativa original y representativa del romanticismo peruano, cuenta con una estructura discursiva en la que Palma particulariza con ligeras descripciones el escenario de la acción presenta a grandes rasgos a los personajes principales y sus actuaciones, a través de hechos narrados con un estilo ameno y un lenguaje plástico y fluido. La anécdota corresponde a algún acontecimiento ocurrido en la realidad, a cuyo conocimiento ha accedido por fuente 
oral o por alguna información escrita, que le dan el hilo para desarrollarla con fantasía y humor.

Suele enmarcarla en el tiempo, ligándola al gobierno de un virrey, del cual presenta un perfil y da noticias de su administración en consonancia con el tema de la anécdota.

Como buen escritor construye la historia principal con interpolaciones, variedad de planos y acciones, dentro de un discurrir, manejado por el interés y el suspenso, que capturan al lector. El tono trasunta su filiación romántica, reivindicando el pasado, lo nacional y sentimental, no con los grises de la tristeza y la desdicha sino con los colores del humor y la picardía.

\subsection{Fondo}

Un virrey hereje y un campanero bellaco refiere un hecho real convertido en texto literario, en el cual Palma cuenta que en 1656, cuando gobernaba el Perú el decimoséptimo virrey "don Luis Henriquez de Guzmán, conde de Alba de Liste y Villaflor y descendiente de la casa real de Aragón, fue el primer grande de España que vino al Perú con el título de virrey, en febrero de 1655, después de haber servido igual cargo en México". Tuvo un período corto de seis años y su administración se caracterizó "por un cúmulo de desdichas" (Tradiciones peruanas completas, Editorial Aguilar, Segundo Ed., Madrid, 1953, pág. 402).

En cuanto a su personalidad, Palma lo anuncia como "Magistrado de buenas dotes administrativas y hombre de ideas algo avanzadas para su época..." (Ibidem), conformándose con estas caracterizaciones suficientes para la historia, aunque dejando para el lector completar con su imaginación el retrato. 
Las atribuidas "ideas algo avanzadas para su época” se refieren a los enfrentamientos que había tenido en México con el alto clero de esa región y que habían determinado que lo rodearan de cierta fama de hereje.

El otro personaje de esta tradición es el campanero, “un limeño llamado Jorge Escoiquiz, mocetón de veinte abriles, (que), consiguió vestir el hábito (de los agustinos); pero como manifestase más disposición para truhanería que para el estudio, los padres, que no querían tener en su noviciado gente molondra y holgazana, trataron de expulsarlo" (Ob.cit., pág. 401 ).

Haber encontrado a Jorge Escoiquiz, un sacerdote protector, le valió que se quedara en el monasterio agustino no como seminarista sino como campanero de la iglesia de San Agustín.

\subsection{La anécdota}

El núcleo literario de la tradición está constituido por el comportamiento del campanero en relación al virrey.

En aquellos tiempos era obligación de las iglesias repicar las campanas cuando pasaba el virrey. Un domingo ocurrió ello y Escoiquiz, que ya ejercía ese oficio, no tocó las campanas. Tal omisión dio lugar a que el virrey comentara en una reunión social como desatención del prior del convento; noticia que llegó a oídos del religioso. Enterado este concurrió a palacio a aclarar lo sucedido y a pedir disculpas. A su retorno a la congregación, Escoiquiz fue azotado por su descuido y el problema ocasionado.

Este hecho no es el central; está narrado como un antecedente, porque si bien el no repicar las campanas el domingo que pasó el virrey fue una falta del campanero, este se prometió a sí mismo vengarse del virrey por el castigo recibido. 
La ocasión se presentó a corto plazo. El virrey, con la aureola popular de hereje, pasó por San Agustín en altas horas de la noche, en una salida secreta para efectuar una visita sentimental. Escoiquiz, que escuchó el ruido del carruaje, echó al viento las campanas, causando un alboroto en la ciudad por lo inusual del horario, enterándose la población de las escapadas clandestinas del gobernante.

El escándalo dio lugar a que el virrey convocara al campanero a su despacho. Del diálogo entre ellos se vio como resultado que el virrey modificó la ruta de sus visitas nocturnas para no pasar por San Agustín y así evitar el repique de las campanas; y que después de unas pocas fechas, Jorge Escoiquiz regresara al noviciado con el padrinazgo del propio virrey, siendo relevado del oficio de campanero, dentro del cual tuvieron lugar estos acontecimientos, propios del núcleo del texto.

\section{La presencia del Derecho}

Esta tradición ilustra las relaciones entre el poder civil, representado por el virrey, y el poder religioso, encabezado por el arzobispo.

La acción del repique de campanas, como saludo a la presencia del virrey, expresa el reconocimiento de su autoridad y la subordinación del clero a su gobierno.

La figura se ubica en el Derecho Público y dentro de las normas del protocolo; es decir, las formalidades y ritos dirigidos a manifestar el respeto a la jerarquía legal del gobernante y a la subordinación.

Ambos incidentes evidencian las relaciones tensionales entre uno y otro poder y los cuidados por no alterarlas, para evitar 
dificultades mayores en el flujo de la convivencia en las esferas de la administración virreynal.

3.1 Otros incidentes indiciarios del conflicto por la supremacía del poder, en este texto.

Don Luis Henriquez de Guzmán, conde de Alba de Liste y de Villaflor, decimoséptimo virrey del Perú, enfrentó un problema con la Inquisición. Fue denunciado públicamente, desde el púlpito de la Catedral, como poseedor de un texto, cuya lectura se encontraba prohibida en el Index. El virrey se sintió indignado y recurrió en queja al rey, quien dirimió llamando la atención al Tribunal y exhortando al virrey para entregar la publicación.

En abono a los conflictos entre la autoridad civil y la autoridad religiosa, la historia central de la tradición se complementa con la relación de otros hechos como los incidentes: a) del quitasol; b) de la consagración obispal; c) la excomunión de los alcaldes de corte; y, d) la provisión de los beneficios eclesiásticos.

Respecto al quitasol, el virrey recurrió en queja al rey, el que, a su vez, resolvió disponiendo que ni su representante ni el arzobispo usaran quitasol.

En cuanto a la excomunión como arma de la Iglesia, empleada por el arzobispo, este fue obligado por el virrey a retirarla.

Otro incidente entre el virrey y la Inquisición se dio por su médico acusado de luteranismo. Fue obligado a entregarlo al Tribunal, pero la acción como poder civil logró que no lo sentenciaran a muerte, sin poderlo librar del proceso, la prisión y la tortura. El Tribunal de la Inquisición o Tribunal del Santo Oficio fue creado por Felipe II en 1569 y, según 
Alberto Tauro del Pino, instalado en Lima en 1570. Funcionó hasta 1820 en que quedó abolido, aunque en 1813 la Corte de Cádiz expidió decreto para extinguirlo. (Enciclopedia Ilustrada del Perú, tomo 16, PEISA, Lima, 2001, págs. 2594-2595)

\section{Conclusiones}

- Desde el punto de vista literario, en la tradición "Un virrey hereje y un campanero bellaco", la historia central del repique nocturno de las campanas, en la salida privada del virrey, proporciona información social y jurídica complementaria, constituyendo el contexto que amplía la visión de las situaciones que son componentes del relato.

- En cuanto al Derecho, aparece a través de los incidentes protagonizados por el virrey, el arzobispo y la Inquisición, en los que se aprecia la pugna por la supremacía del poder civil sobre el religioso; es decir, la conducta del virrey está frecuentemente motivada por hacer sentir y prevalecer su autoridad sobre la del clero.

- Los actos protagonizados corresponden al Derecho Público por pertenecer a las relaciones entre las autoridades de los poderes civil y religioso.

- También se percibe el aspecto procesal en los reclamos, admitiéndose la decisión del rey como última y definitiva instancia.

- El rey surge como órgano máximo de gobierno concentrando facultades y atribuciones legislativas y 
judiciales, puesto que dictaba las normas y administraba justicia administrativa, dirimiendo conflictos.

- Las resoluciones del rey ponen en claro su política de armonización y búsqueda de equilibrio entre ambos poderes. 